Bu beenme gradually exhausted, and did not long survive the formation of the second abscess. Unfortunately a post mertem examination could not be obtained. In this case there was great dullness on percussion over a considerable portion of the right side, and only slight respiratory murmur could be heard anteriorly at the upper part of the chest, in the subclavicular space, and posteriorly near the spine.

Dr. Aran cites two cases of thoracentesis for acute (purulent) pleurisy by Dr. Trousseau, but both terminated fatally at last, which was not remarkable, as they were complicated with other serious affections. Dr. Trousseau had also operated four times for chronic purulent pleurisies, but all terminated fatally at no distant period.

From the pyogenic disposition of the pleural membrane, and therefore the great disposition to relapse after thoracentesis, it becomes a question, and a very momentous one in preventing a fatal termination, so common in this disease, how far we may be able to counteract a recurrence of the effusion by the use of injections, and most effectively perhaps by the use of iodine ones. $M$. Boinet has referred to three cases where they have been employed, once by himself, once by M. Boudant, and once by M. Massiani. In the last case a cure was effected in three months, but with considerable deformity of the chest ensuing, along with depression of the corresponding shoulder, and lateral inclination of the vertebral column. It is well known since the researches of Laennec, * that this change may follow a natural cure, and was indeed referred to in my former paper, as occurring in Mr. Burton's patient, Mr. Liversedge, the artist. In M. Boudant's case, a cure was effected in six months, but with some sinking of the ribs, and slight devintion of the sternum. In M. Boinet's case, a cure was effected in four months, but with flattening also of the ribs. In al these three cases, air was admitted into the chest, which probably modified injuriously the character of the fluid. If this admission of air be prevented, either totally or almost so, by making a valrular opening, as I did in each of the three operations on Norris, a speedier cure may be expected, with less subsequent contraction of the chest, probably from the readier adhesion of the opposing membranes, and consequent obliteration of the pleural cavity.

In two cases operated on by Dr. Aran also in this way, one of acute and the other of chronic pleurisy, the former terminated fatally by the supervention of subacute peritonitis; but the latter, occurring in a locksmith, aged 24 , and of fifteen to eighteen months' duration previous to treatment, terminated successfully after a single iodine injection.

When we consider the result of the treatment of these six cases of pleuritic effusion by iodine injection, five out of the six being successful, and that the other would not improbably have been so also, had it not become complicated with another affection,-it must, I think, be conceded that it is one offering considerable advantages.

I am not aware of any other case besides the one related in this paper having been yet treated similarly in this country ; but from the satisfactory result in this one instance, conjoined to those of a few similarly treated abroad, I think we are encouraged to give it a further trial in cases apparently adapted for it. Such cases seem to be those of chronic uncomplicated pleuritic effusion. Similar success could scarcely be expected when this empyema is the result of a vomica or vomices bursting into the pleural cavity, or where the effused fluid has been suffered to remain so long as to form external communication through the parietes of the chest, or where both these states are coexistent. Of all these forms and complications, I doubt not, most have seen examples; and instances of them are referred to both in this and in the former paper. However, even in such circumstances, where a permanent cure is unattainable, great temporary relief to the oppression and

- Perhaps I may be permitted to state, that In the year 1822, I had an oportunity of accompanying Leennec in the wards of the Hopital Necker, of ortunity of accompanying Laennec in the wards of the Hopers and then introdncing into this part of the country their ves: one was for my old friend introdecing into this part of the country their nee: one ras dyspnces is often afionded by the operation of thoracentecia The process itself of withdrawing the fluid by the use of the trocar and canula alone, without any previous incision or dissection, is one of extreme simplicity; and, though I have now performed it mauy times, no unpleasant accident has ever occurred.

Manchester, Soptember 1854.

\section{CASE OF HYDROCEPHALUS IN A CHILD, SIX MONTHS OLD, IN WHICH THE HEAD} WAS TAPPED EIGHT TIMES.

By J. D. BROWN, Esq.

A cHILD, six months old, with chronic hydrocephalus, wres placed under my care on July 10th, 1852. I enclosed the head with straps of adhesive plaster, and persevered in this plan for some time. No good effects were produced. I now proposed tapping, to which the parents consented. Mr. Rowe was called into consultation, and assisted.

August 6th. We removed six ounces of serum. The child became a little sick and faint.

August 7 th. The child was apparently much improved; it looked more intelligent, and took greater notice of the nurse. The head was tightly strapped up.

August 18th. The head was as large as ever. It was tapped to six ounces, with the same results.

September 6th. The head was larger than it had been at all; and it was tapped to eleren ounces, with the same results as on the previous occasions.

September 28th. The head was again larger; and twenty ounces of fluid were removed by tapping, with the same results.

October 8th. The head was tapped to eleven ounces.

October 18th. Tapping was performed, and sixteen ounces of fluid were removed.

October 25th. Twelve ounces of fluid were withdrawn.

October 30th. We now abandoned tapping as useless, and inserted a seton of silk through the membranes of the brain, running it along the interior for an inch before bringing it out. No immediate result was produced; but a great quantity of serum flowed from the orifices through which the seton passed. At the end of twelve hours, there was no change. At the end of twenty-four hours, there were vomiting, restlessness, and expressions of pain and distress. In thirty-six hours, there appeared twitching of the muscles and startings, bordering on convulsions. In forty-ejght hours from the introduction of the seton, the child refused his food. Moaning and approaching stupor were now observed. The seton was now removed; and these symptoms gave way in a day or two. The head was by this time much decreased in size, and continued so for several days.

We now flattered ourselres with hopes of a cure; but in another day or two, cvident signs of secretion manifested themselves, and at the end of twelve days we tapped again, and again the fluid collected. We now gave up all hope, and allowed the disease to take its course. The head attained a frightful size; and the child died.

Examination of the Body. A large washhand basin full of serum was taken out of the brain. The containing sac was formed by the brain, which was completely unfolded, and so stretched, that it was no thicker than the dura mater. This fact, in our opinion, accounted for the failure of the treatment. IIad the water been contained in the membranes instead of in the rentricles, there would have been a better chance of success.

I would never hesitate to make similar attempts at a cure, with the hopes of the membranes being the investing envelope of the water. In such cases, a happy termination might be expected.

Haverforàwest, October 1854 